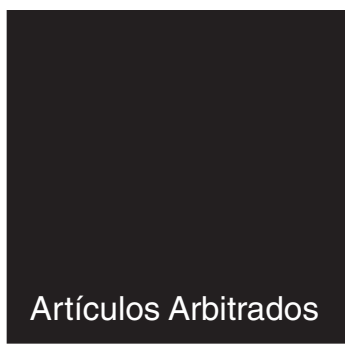

\title{
Las villas de emergencia y sus viviendas en las racionalidades políticas de las autoridades socialistas del Departamento Ejecutivo Municipal de Rosario [1989-2007]
}

\section{Martín Carné}

Doctor en Ciencia Política (Universidad Nacional de Rosario). Docente en la Facultad de Ciencia Política y Relaciones Internacionales de la Universidad Nacional de Rosario y en la Facultad de Derecho y Ciencia Política de la Universidad Católica de Santa Fe. Colaborador externo de la Organización Internacional del Trabajo (2014). Becario posdoctoral del Consejo Nacional de Investigaciones Científicas y Técnicas, Facultad de Ciencia Política y RRII, Universidad Nacional de Rosario.

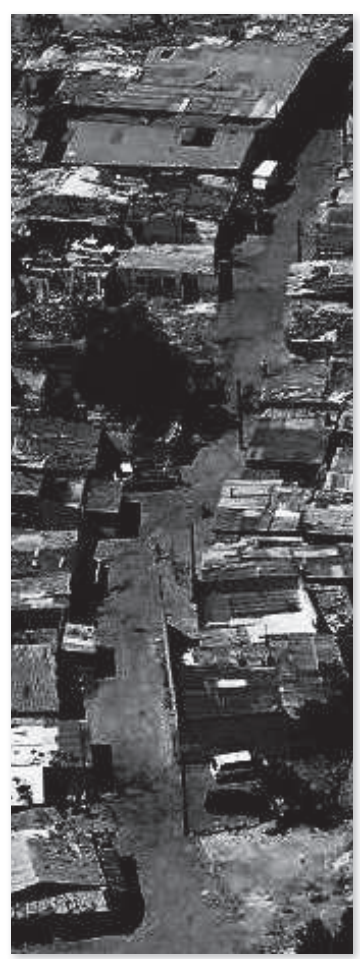




\title{
Resumen
}

El trabajo examina las racionalidades políticas de las autoridades socialistas del Departamento Ejecutivo Municipal de Rosario para, en materia habitacional, gobernar entre 1989 y 2007 a la población asentada en las villas de emergencia de la ciudad con la hipótesis de que tales racionalidades incorporaron a lo largo del período razonamientos y cálculos asociados con el neoliberalismo y el workfarismo, tendiendo así tanto a involucrar a esta población en su mejoramiento habitacional como a compensar déficits de infraestructura y equipamiento en las villas ideando herramientas normativas promotoras del lucro de actores del sector privado vinculados con el desarrollo del mercado inmobiliario.

Palabras clave

Villas de emergencia; vivienda; racionalidades políticas; Departamento Ejecutivo Municipal; Rosario.

\begin{abstract}
Shantytown and shantytown housing in the political rationalities of Rosario's Municipal Executive Department's socialist authorities (1989-2007)

The paper analyzes, between 1989 and 2007, the political rationalities of the housing policies of the Rosario Municipal Executive Department's socialist authorities to manage the habitat of, , the population living in the city's shantytowns. It follows the hypothesis that such rationales progressively incorporated reasoning and calculations associated with neoliberalism and workfareism tending to involve that population in housing improvement and alleviate their infrastructure and equipment deficit through regulatory tools that fostered the profit of private sector actors involved in the development of the housing market.
\end{abstract}

Key words

Shantytown - House - Political rationalities - Municipal Executive Department-Rosario. 
1. El autor agradece los comentarios de los evaluadores de la revista, quienes quedan exentos de las eventuales imprecisiones de este documento.

2. Se acuerda con GUBER, quien considera "villera" a la población de las clases sociales subalternas que, excluida de toda propiedad, "se encuentra articulada en una posición asimétrica y subordinada a los sectores hegemónicos" (1984: 115). La adjetivación "villero/a" no guarda carga peyorativa; por el contrario, pretende evitar expresiones frecuentemente eufemísticas como "habitante de asentamiento/barrio informal/irregular". e ilegalidad que amenazan tal gobernabilidad social, y estando también su población matizada por la presunta posesión de hábitos moralmente reprobables (poca laboriosidad, propensión al desorden, dependencia fraudulenta de la asistencia estatal), el alto número de villas dispersas en la trama urbana rosarina y la magnitud de la población albergada en 2004, unos 155 mil habitantes en 91 villas (GARZIA ET ÁL., 2004)— junto con el débil anclaje territorial del que partió el hoy PS (GuBERMAN, 2004), se vuelve legítimo el interés por describir las racionalidades políticas de las autoridades del DEM de Rosario para el gobierno (en materia habitacional entre 1989 y 2007) de la población villera ${ }^{2}$, caracterizando las conceptualizaciones dadas a tales villas y a las viviendas pensadas para su población. 
Dado el objeto de estudio expuesto, se advierte que el presente trabajo no analizará prácticas concretas de las autoridades del DEM o de la población en cuestión, sino que examinará, de las primeras, "la reflexión sobre la mejor manera posible de gobernar [...] La instancia de la reflexión en la práctica de gobierno y sobre la práctica de gobierno [...] la racionalización de la práctica gubernamental" (FoucAult, 2007: 17), para así reconocer cambios y continuidades en las formas de pensar el ejercicio de poder (a quién gobernar, cómo y según qué criterios de conveniencia, etc.). Esto no significa reducir a los segundos a la pasividad ni asumirlos como meros receptores de esquemas normativos hegemónicos que los determinan y condicionan unilateralmente (GuBER, 1984). Implica considerarlos - estrictamente a los fines del análisis-desde la óptica de quien procura gobernarlos, sin desconocer que la población villera también pueda tener sus propios cálculos y razonamientos (los que no son aquí objeto de estudio) sobre cómo operar en esa relación de poder.

Las fuentes consultadas para dar cuenta de las racionalidades políticas en cuestión fueron las siguientes: $a$ ) documentos municipales (decretos, discursos de apertura de sesiones legislativas a cargo de intendentes, publicaciones oficiales de divulgación) referidos a programas habitacionales del DEM implementados en el período seleccionado; $b$ ) documentos de organismos internacionales de crédito (OIC) vinculados financiera y conceptualmente con tales programas; $c$ ) documentos de think tanks del PS y $d$ ) notas periodísticas con testimonios de las autoridades del DEM sobre el tema. Estos documentos recogen los discursos que expresan las racionalidades políticas, las que se articulan a través del lenguaje. En palabras de Rose y Miller, "el análisis del discurso político ayuda a elucidar el sistema de pensamiento a través del cual las autoridades han señalado y especificado los problemas de gobierno además del sistema de acción a través del cual han tratado de poner en práctica el gobierno” (1992: 177, traducción del autor).

La hipótesis de trabajo sostiene que, para el gobierno de la población villera, en materia habitacional tales racionalidades incorporaron progresivamente (a lo largo de los subperíodos (1989-1995, 1996-2001 y 2002-2007) razonamientos, reflexiones y cálculos asociados al neoliberalismo y al workfarismo (tales como proactividad, emprendedurismo, autosubsistencia y responsabilización), tendiendo así, por una parte, a involucrar a esa misma población en su mejoramiento habitacional y, por otra, a mitigar el déficit de infraestructura y equipamiento en las villas ofreciendo herramientas normativas favorecedoras del lucro de actores del sector privado vinculados con el desarrollo del mercado inmobiliario. 
Las villas de emergencia y sus viviendas en las racionalidades políticas de las autoridades socialistas del Departamento Ejecutivo Municipal de Rosario (1989-2007)

El trabajo se organiza con un primer apartado que presenta la noción de racionalidades políticas y su afiliación a los llamados estudios de la gubernamentalidad. Los tres apartados siguientes caracterizan dichas racionalidades para los subperíodos arriba mencionados. El primero de ellos (intendencia Cavallero) se liga con el despliegue del proceso de Reforma de Estado ${ }^{3}$, en virtud del cual las autoridades municipales se debatieron entre demandar respuestas habitacionales al Estado nacional y ensayar sus propias intervenciones, oscilando asimismo entre relocalizar las villas y/o rehabilitarlas progresivamente. El segundo (intendencia Binner) comprende las manifestaciones —en términos de empobrecimiento- del alto desempleo registrado en la ciudad ligado a la recesión iniciada en 1998. Aquí, los recursos obtenidos del endeudamiento con OIC consolidaron la opción de mejorar in situ las villas y apuntaron además a operar en la población villera cambios aptitudinales y actitudinales que dieran sustentabilidad a tales mejoras. El último período (intendencia Lifschitz) remite a años en los que la recuperación económica y ocupacional -y el rol asumido por el Estado nacional-planteó cambios y continuidades en las formas de pensar — desde el plano habitacional- el gobierno de la población villera. Para concluir, los comentarios finales reúnen sintéticamente la evidencia hallada.

\section{Las racionalidades políticas en el marco de los estudios de la gubernamentalidad}

Buena parte de las teorizaciones que Michel Foucault realizó a fines de los años 70 en el Còllege de France fue recogida por anglofoucaultianos $^{5}$ como Rose y Miller (1992), O’Malley (2004), Dean (2006), entre otros, quienes contribuyeron a forjar la perspectiva analítica de los governmentality studies ${ }^{6}$. Central para quienes cultivan esta línea de investigación es el concepto de gobierno, el cual no es asimilado a un locus en el Estado ni a una función exclusiva de quienes acceden a él. Gobierno designa más bien una relación de poder en la cual se procura dirigir la conducta de otro u otros (incluso la conducta propia) estructurando su campo de acciones posibles para así alcanzar un
3. Se alude al paquete de medidas (privatización de empresas estatales, descentralización de servicios a Estados provinciales y ajuste de agentes públicos) que en la última década del siglo $X X$ se orientó - en Argentina y otros países de la regióna redefinir organizativa y funcionalmente el Estado nacional, reducir su gasto y otorgar al mercado una mayor intervención en la asignación de recursos.

4. En particular los seminarios de 1977-1978 y 1978-1979 publicados por Fondo de Cultura Económica con los nombres Seguridad, territorio, población y Nacimiento de la biopolítica. 5. El término remite a investigadores que, procedentes originariamente de países como Reino Unido, Australia, Canadá, delinearon desde fines de los años 70 y comienzos de los 80 los estudios de la gubernamentalidad. 6. Para mayor información sobre el trasfondo históricointelectual en el que fue cobrando forma esta "corriente" de análisis, así como sus áreas de investigación y limitaciones conceptuales, consultar ROSE, O'MALLEY Y VALVERDE (2012). 
determinado fin estratégico (Foucault, 2001). Esta tarea, sea o no por intermedio del Estado, necesariamente implica contar con una gubernamentalidad: un conjunto de "instituciones, procedimientos, análisis y reflexiones, cálculos y tácticas que permiten ejercer esa forma específica y compleja de poder" (Foucault, 2006: 136) que es el gobierno.

Un esquema frecuentemente utilizado desde este enfoque para analizar el cómo de tal gobierno combina —a modo de "tríada" (GRondona y HaIdAR, 2012) — las dimensiones de a) racionalidades políticas, b) programas de gobierno y c) tecnologías de poder. Como regularidades discernibles a nivel discursivo, las primeras —objeto de estudio aquí analizado- designan formas de pensar y razonar que - con cierta coherencia-dirigen la acción de quien interviene en una relación de poder hacia determinados objetivos, permitiendo calcular tácticas y estrategias con las cuales alcanzarlos (GoRDon, 1991). En efecto, el gobierno, como toda práctica, implica un pensamiento, una mentalidad que lo conceptualice, que defina epistemológicamente a quién gobernar, bajo qué valores morales, de acuerdo con qué saberes y en función de los motivos que justifican sean unos y no otros quienes gobiernen.

En tanto principios que dotan de inteligibilidad y sentido a las cosas ubicándolas en un orden, estas racionalidades permiten problematizar una situación en procura de resolverla. Una problematización forma aquello que en sí mismo no tiene positividad para volverlo pensable e intervenible; elabora "las condiciones en las que se pueden dar respuestas posibles, definiendo los elementos que constituirán lo que las diferentes soluciones se esfuerzan en responder. Esta elaboración de un tema en cuestión, esta transformación de un conjunto de obstáculos y dificultades en problemas a los que las diversas soluciones buscarán aportar una respuesta, es lo que constituye el punto de problematización y el trabajo específico del pensamiento" (Foucault, 1999: 360), trabajo que busca desarrollar líneas prácticas y operativas para su tratamiento. Sin ser las únicas, las racionalidades políticas más estudiadas desde la óptica de la gubernamentalidad han sido el liberalismo, el welfarismo (propio del Estado de Bienestar Keynesiano, EBK) y el neoliberalismo.

A su turno, los programas de gobierno traducen las racionalidades políticas en objetivos que alcanzar y prescriben una secuencia de operaciones con las cuales intervenir los objetos de la realidad, de modo tal de adecuarlos a la lógica de esas mismas racionalidades. Por último, las tecnologías de poder inscriben las racionalidades en el ejercicio práctico del poder. Rose y Miller las definen como "el complejo de programas, cálculos, técnicas, documentos y 
Las villas de emergencia y sus viviendas en las racionalidades políticas de las autoridades socialistas del Departamento Ejecutivo Municipal de Rosario (1989-2007)

procedimientos a través de los cuales las autoridades tratan de dar efecto a sus ambiciones gubernamentales” (1992: 175, traducción del autor). Exámenes, capacitaciones para inculcar hábitos, inspecciones son ejemplos de técnicas que efectivizan el gobierno produciendo significados que determinan y modulan la experiencia de los sujetos, transformándolos ( $\mathrm{P}_{\mathrm{A}-}$ PALINI ET ÁL., 2012). Las racionalidades políticas son entonces una propiedad de toda práctica de gobierno. Analizándolas se puede reconocer el “código' que rige las formas de hacer las cosas" (Foucault, 1991: 79).

Si bien las teorizaciones de esta perspectiva suelen ser criticadas (Grondona y HAIDAR, 2012) por descuidar la producción de evidencia empírica que las respalde o por subestimar el rol del Estado (aspecto relevante para Argentina y los países de la región), ella tiene, por otro lado, la bondad de contribuir a evitar explicaciones monocausales de los fenómenos sociales contemporáneos al analizar cómo pueden converger racionalidades y tecnologías de distinto orden en las prácticas concretas de gobierno. En este sentido, debe recordarse que ese par no se reemplaza o sucede "en bloque" uno a otro; por el contrario, racionalidades y tecnologías se combinan local y contingentemente procurando resolver situaciones que requieran ejercer poder, pudiendo articularse retóricas welfaristas de solidaridad social y neoliberales de empoderamiento (DE MARINIs, 1999) con técnicas disciplinarias (evaluaciones, capacitaciones, por ejemplo).

\section{Neoliberalismo y workfarismo como racionalidades políticas}

El neoliberalismo no es un cuerpo teórico coherente y original, sino más bien un conjunto de saberes, tecnologías y prácticas que implican una determinada racionalidad política (GAGo, 2014) que asigna al Estado y al sujeto roles específicos. A estos últimos los concibe activos, autónomos, poco dependientes de estados desarrollistas o de bienestar que, al garantizar derechos sociales (proveyendo bienes y servicios públicos), los condenarían presuntamente a la dependencia y la pasividad e inducirían entre ellos una igualación relativa que atentaría contra la necesaria desigualdad sobre la base de la cual la competencia fije precios en el mercado (Foucault, 2007). Si en la mirada welfarista la sociedad debe garantizar a sus miembros el goce de un conjunto de derechos que los integran a la vida en común, para el neoliberalismo son los sujetos los responsables de tal integración ganándose autónomamente la vida (Kymlicka y Norman, 1997). 
Emprendedores y responsables de su destino, los sujetos así proyectados son empresarios de sí, empresarios del capital humano que portan, gestores cuyas decisiones (en materia de educación, uso del tiempo libre, vivienda) están crecientemente regidas por criterios de inversión que sirvan para competir mejor en el mercado (HARVEY, 2007). Estos sujetos son estimulados a responsabilizarse por elegir cómo conducir sus vidas de manera autónoma, y es hacia esa libertad de elección, hacia sus gustos y deseos, que se dirigen las técnicas que procuran gobernarlos, técnicas que aprovechan la energía que los mismos sujetos aportan. Al ser racionales y aceptar las oportunidades y constreñimientos de la realidad, estos empresarios adaptan su conducta a cualquier modificación del ambiente, con lo que basta operar allí algún cambio para inducir en aquellos comportamientos predefinidos, lo que equivale a gobernarlos (Foucault, 2007).

En cuanto al Estado, la concepción neoliberal es la de uno "mínimo", administrador de justicia y poco regulador de la actividad económica (liberalización comercial y financiera, flexibilización laboral), fiscalmente equilibrado, que deja a la iniciativa privada organizar la producción y distribución de bienes y servicios ("Estado subsidiario”). Sus intervenciones de corte social deben implementarse de manera no universal y transitoria, asistiendo solo a quienes corren riesgo de no poder competir en el mercado, algo que en los hechos sustituye "un marco de derechos y garantías que obligue a asistir a los grupos sociales [...] excluidos del mercado, por acciones volátiles y focalizadas en las 'carencias'” (Grassi, 2003: 31). Dichas intervenciones deben atenuar los efectos de la pobreza antes que corregir los mecanismos que la determinan. Además, rechazando la presunta pasividad a la que habrían conducido los programas sociales típicos de los EBK, el neoliberalismo atribuye a sus destinatarios la responsabilidad de merecer los beneficios que aquellos confieren exigiendo contrapartidas laborales o de reconversión laboral (workfare) con las que mantenerse. Esta racionalidad workfarista, surgida en Estados Unidos a fines de los años 60 como crítica a la supuesta dependencia generada por los esquemas estatales de bienestar social, enfatiza las obligaciones (trabajar, buscar empleo, incorporar destrezas laborales) correspondientes a sus beneficiarios y supone "prestar beneficios residuales [...] a los ingresos no asalariados, contingentes con las condiciones del mercado de trabajo y de empleabilidad individual” (Реск, 2002: 342, traducción del autor). 
Las villas de emergencia y sus viviendas en las racionalidades políticas de las autoridades socialistas del Departamento Ejecutivo Municipal de Rosario (1989-2007)

De la relocalización a la rehabilitación in situ (1989-1995)

Villa de emergencia es el nombre generalmente dado a las urbanizaciones no planificadas, no amanzanadas, desarrolladas al margen de la normativa urbanística, que ocupan terrenos fiscales o privados vacantes, cuyas viviendas - carentes de adecuado acceso a servicios públicos- suelen construirse con materiales inapropiados y cuyos hogares expresan distintas manifestaciones de pobreza urbana (VARELA Y CRAVINo, 2008) ${ }^{7}$. Más allá de su valor descriptivo, tal conceptualización puede prestarse a "cosificar" estas formas sociales opacando que se trata de un hábitat complejo, "socialmente producido [...] en el que los hogares disponen de alguna organización social [...] y que, a pesar de las limitaciones de recursos que poseen, sus integrantes disponen estrategias de supervivencia que despliegan cotidianamente para vivir y construir su hábitat” (BARRETO, 2010: 174).

En la racionalidad de las autoridades del DEM asumidas en diciembre de 1989, las villas eran un fenómeno causado por "las migraciones provenientes de las provincias del nordeste [...] Gente corrida por el hambre y la miseria de sus lugares de origen que [deciden] desarraigarse para terminar ocupando terrenos fiscales y ferroviarios en nuestra ciudad. Rosario se ve obligada a solucionar solidariamente los problemas que la Nación fundamentalmente -y también la provincia-no solucionan [...] Por esto la Nación tiene que cubrir y brindar atención para paliar un déficit producido por una falta de desarrollo interior" (Diario La Capital, 16/02/90, negritas del autor). De este modo, las autoridades socialistas del DEM procuraban descargar responsabilidades por la expansión de las villas y las paupérrimas condiciones de sus viviendas atribuyendo a escalas estatales superiores las competencias legítimas sobre la problemática. Asimismo, el discurso refleja la primacía que ellas todavía asignaban al Estado nacional (en proceso de reforma estructural) en la promoción del desarrollo socioeconómico del país y el rol de poder delegado que reservaban para el Estado municipal.

Cosificándolas y haciendo abstracción de los procesos sociales que las determinaban, las villas del territorio se presentaban a las autoridades socialistas como un problema para el desarrollo de obras públicas: ellas interrumpían calles y obstaculizaban la "planificación armoniosa y coherente de la ciudad" (Concejo Municipal de la CiUdAd de Rosario, 1991: 21, en adelante CMCR). Como un tumor en el tejido urbano, la masa amorfa de ranchos no hacía juego con ella. Había que erradicar y relocalizar estos asentamientos y a las familias que

\author{
7. De acuerdo con \\ BARRETo (2010), las \\ precarias condiciones \\ en las que vive la \\ población que se \\ asienta en estas \\ "áreas urbanas \\ deficitarias críticas" \\ no responden \\ solamente a \\ un problema \\ habitacional, \\ sino a déficits \\ en dimensiones \\ interrelacionadas: \\ jurídica \\ (irregularidad \\ de tenencia del \\ suelo); económica \\ (desocupación, \\ informalidad \\ laboral); social (baja \\ educación, ausencia \\ de cobertura de \\ salud y de haberes \\ previsionales); \\ cultural \\ (estigmatización); \\ habitacional \\ (hacinamiento, \\ precariedad \\ de materiales \\ constructivos), entre \\ otras. Para revertir \\ dichos déficits, \\ las intervenciones \\ estatales \\ deben abordar \\ integralmente estas \\ dimensiones.
}


los habitaban, procurando "un ordenamiento progresivo [...] de las ocupaciones irregulares" (CMCR, 1991: 32) para “liberar espacios públicos” (CMCR, 1991: 42). Así, las villas debían ser sustituidas por conjuntos de viviendas ordenados en la trama disciplinada de la ciudad.

Con respecto a la vivienda, su relevancia radica en hacer de soporte de la reproducción de los individuos que la habitan. Protege del clima, facilita la higiene, el descanso, la recreación y la alimentación de quienes aloja, siendo en esencia una compleja configuración de servicios (RAGGio, 1995). La precariedad de la vivienda villera (superficie, circulación de aire, alojamiento, materialidad, estado dominial) condiciona la diferenciación de funciones domésticas antes mencionadas y los roles familiares (reproducción, sexo legítimo), con lo cual su papel de "regulador de un conjunto de servicios y ordenador de actividades y cuerpos, que diferencia, reúne o separa" (BALLENT, 2007: 414) se presta a situaciones de hacinamiento, de promiscuidad sexual, de incertidumbre sobre desalojos y déficits de confort que pueden predisponer, en los sujetos que las habitan, conductas distanciadas de las socialmente convalidadas.

Las viviendas sociales tradicionalmente construidas por el Estado nacional seguían la modalidad llave en mano: núcleo básico inicial (estructura prefabricada de instalaciones sanitarias) y un ambiente de $40 \mathrm{~m}^{2}$, con mampostería de ladrillos y techo de hormigón armado (Equipo para el Estudio de la Vivienda, 2001). Esta construcción de viviendas estandarizadas y seriadas tributaba a la convicción de que ellas podían atemperar las desigualdades económicas ligadas a la producción capitalista e inducir nuevos comportamientos en la población, posición propia del determinismo ambiental asociado al paradigma de la Ecología Urbana expresado por miembros de la Escuela de Chicago en las primeras décadas del siglo XX, según el cual toda forma espacial causa formas culturales.

En 1994, la villa y su vivienda cambiarían en el pensamiento de las autoridades del DEM. Se reconocía que "no basta agregar a la villa en forma aislada 'aquello que le falta' para que la ciudad absorba sus situaciones de periferia, sino que solamente a partir del desarrollo de programas de rehabilitación integrados a estrategias urbanísticas más amplias es posible producir una inserción efectiva de la villa en la ciudad y de los villeros en los mecanismos de producción y vida en sociedad" (Municipalidad DE Rosario, 1994: s/n, en adelante, MR). Para el Programa Convivencia lanzado en ese momento, las villas se incrementaban año a año evidenciando la insuficiencia de las soluciones ensayadas para revertir sus características. 
"Se ha hecho aparecer al asentamiento de villa como un fenómeno casi patológico que se desarrolla y degrada en el tejido de nuestras ciudades y no como una de las formas concretas que la ciudad asume, como expresión extrema de la marginación y la pobreza" (MR, 1994: s/n). Al ser la villa una manifestación casi natural de la ciudad, la tarea a emprender ya no era erradicarla, sino rehabilitarla in situ conteniendo su expansión y trazando sus calles internas para ensamblarla al entorno barrial. La villa era así recuperable llevando soluciones habitacionales ${ }^{8}$, polideportivos, plazas, equipamiento de uso comunitario, "preservando lo que la población y a tiene incorporado como valores: la elección del lugar, el modo de vida, las formas de habitar, lo construido" (MR, 1994: s/n). Todo un reconocimiento de la conveniencia de no oponerse a los intereses de los individuos, sino potenciarlos, promoverlos; una suerte de principio regulador de las prácticas apropiadas para gobernarlos que además permitía economizar la energía desplegada por las autoridades del DEM.

La relocalización de la población villera iba considerándose contraproducente, ya que si bien contribuía al ordenamiento territorial del área desocupada y la vivienda nueva mejoraba las condiciones de vida de la población, ella acarreaba pérdida de vínculos con vecinos, afectaba changas (fuente de ingresos) y suponía la conflictiva adaptación a un nuevo entorno urbano. Por otro lado, el territorio de destino para esta población debía ser provisto de la infraestructura de servicios necesaria, cuya expansión significaba altos costos económicos, dada su ubicación periférica dentro del ejido urbano.

En esta estrategia de fundir paulatinamente la villa en su entorno próximo, villa y villero cedían lugar al barrio y al habitante (MR, 1994: s/n). Tomaba cuerpo un nuevo cálculo con el cual procurar el gobierno de esta población, según el cual resultaba más conveniente y económico para las autoridades conocer y estimular su deseo en cuanto a dónde asentarse, cómo disponer el espacio que habitar, cómo construir su vivienda y con quién relacionarse. Ajustar y diversificar la oferta de soluciones habitacionales a la demanda y no viceversa era el análisis que guiaría la racionalidad de las intervenciones estatales. Si esta población elegía permanecer en la villa, era prudente aceptar tal decisión; ello ayudaba a no desanudar las redes de ayuda mutua que permitían paliar la siempre insuficiente asistencia estatal y contener eventuales descontentos o malestares grupales.

Esta nueva racionalidad tributaba a elaboraciones teóricas surgidas a fines de los años 60 (JarAmillo — 1990 - las denominaría la "versión de izquierda” de la Teoría de la Marginali-
8. Por soluciones habitacionales se alude no solo a la provisión de nuevas viviendas por parte del Estado, sino a un menú de intervenciones que comprende desde regularización dominial del terreno vía escrituración, hasta provisión de canastas de materiales (sanitarios, ladrillos, chapas, entre otros) para mejoras o ampliaciones en las viviendas ya construidas y la conexión a servicios. 
9. La propuesta de TURNER de involucrar al usuario en la construcción de su vivienda fue criticada, entre otros, por el colombiano EMILIO PRADILLA (1983), marxista que la consideraba una forma de sobreexplotar a los sectores populares (convalidando salarios que no contemplaban el costo de la vivienda) y retrasar la lucha contra la burguesía y el Estado.

10. La autoconstrucción es la práctica individual o colectiva de edificar la vivienda o los componentes del hábitat por parte de los propios usuarios, quienes no necesariamente controlan todo el proceso constructivo. En oportunidades, el término suele intercambiarse - erróneamente-con el de autogestión, modalidad de producción colectiva y organizada que implica que organizaciones populares administren recursos estatales $y$ controlen dicho proceso constructivo (RODRÍGUEZ ET ÁL., 2007).

11. Las localidades del AGR son Rosario, Funes, Soldini, Pérez, Villa Gobernador Gálvez, Puerto General San Martín, San Lorenzo, Granadero Baigorria, Capitán Bermúdez, Fray Luis Beltrán y Roldán.

12. El porcentaje de población pobre e indigente del AGR ascendía a 36,6\% en octubre de 1996 (CASTAGNA ET ÁL., 1997). dad derivada de la Teoría de la Modernización) que criticaban los costosos procesos centralizados de provisión habitacional seguidos en la región para atender la demanda creciente de viviendas por parte de la población que migraba del campo a la ciudad, argumentando que la mejor respuesta al problema de las villas pasaba por respetar la autonomía de los individuos para configurar su propio hábitat. En esta dirección, el arquitecto inglés JoHN TURNER consideraba que "cuando los usuarios controlan las decisiones más importantes y son libres para aportar sus propias contribuciones al diseño, construcción y administración de su vivienda, ambos, el proceso y el ambiente producidos, estimulan el bienestar individual y social" (citado en FERNÁNDEZ WAGNER, 2000: 61) ${ }^{9}$. Además de ser costosa e insuficiente, la producción normalizada de viviendas desconocía la variedad de necesidades y preferencias de la población, frente a lo cual la autoconstrucción ${ }^{10}$ ofrecía más ventajas, entre ellas, menores costos económicos para el Estado, una mejor edificación guiada por el valor de uso más que de cambio de la vivienda, respetando la idea de hacer ciudad sobre la ciudad, esto es, economizar las distancias, los costos y los tiempos de extender redes de infraestructura para servicios y promover la ocupación de las áreas interiores y los bordes vacantes de ya no la villa, sino el barrio.

\section{La villa y su vivienda en el marco del desarrollo de la comunidad (1996-2001)}

La segunda mitad de la década del 90 encontró a Rosario (y su aglomerado ${ }^{11}$, AGR) con tasas de desempleo cercanas al $20 \%$, hecho que endureció las condiciones de vida de una amplia franja poblacional ${ }^{12}$. Eran años en que "los inspiradores internacionales y regionales del ajuste estructural pasaron [...] de la expectativa del derrame de riquezas sobre los más pobres [...] a advertir a los gobiernos acerca de la necesidad de prestar atención a los pobres” (GRAssi, 2004: 192, cursivas y negritas en el original).

En materia de vivienda y mejoramiento barrial para la población villera, de cara a las elecciones de intendente de diciembre de 1995, el Instituto 
Las villas de emergencia y sus viviendas en las racionalidades políticas de las autoridades socialistas del Departamento Ejecutivo Municipal de Rosario (1989-2007)

de Estudios Municipales ${ }^{13}$ (IEM) propuso obtener fondos de OIC y diseñar "operatorias que potencien la autogestión y la participación popular” (IEM, 1995: 45). La problemática de la vivienda pasó a reconocerse como "componente de [otra] mayor: la del hábitat popular, con componentes tales como la calidad de la infraestructura urbano-comunitaria y la calidad de la organización social [lograda esta por] la generación de redes solidarias que favorezcan la participación [...], la cual debe ser observada en sus dos dimensiones: como derecho a la inserción y como deber de implicación” (MR, 1998a: 29, negritas del autor). Esta retórica "participativista" llamaba a que la propia población villera y sus organizaciones fueran responsabilizándose de su vivienda y hábitat para así descargar al municipio de los costos inherentes a la tarea.

El Servicio Público de la Vivienda del Estado local implementó el Programa Solidario para hacer descansar las soluciones habitacionales "en el trabajo solidario de los vecinos a través de la autoconstrucción colectiva o individual” (MR, 1998a: 30), en concordancia con postulados electorales. Sin embargo, estas intervenciones no daban un tratamiento satisfactorio a las villas del municipio, cuya realidad generaba "inseguridad social, impide el desarrollo urbano de grandes áreas y, por ende, las desvaloriza” (MR, 1998a: 30). Para alcanzar tal objetivo se diseñó el Programa de Recuperación y Transformación Urbana (PROSUR), cuyo financiamiento fue gestionado ante el Banco Interamericano de Desarrollo (BID). En años de planificación estratégica, globalización y competencia urbana por atraer inversiones que contribuyan al desarrollo local, se pensaba que con este programa sería factible construir "una ciudad equilibrada y sustentable, que permita reforzar las aspiraciones y deseos de ciudad competitiva" (MR, 1998b: 39, negritas del autor).

El proyectado PROSUR recibió finalmente en el año 2001 el nombre de Programa Rosario Hábitat - Programa Integral de Recuperación de Asentamientos Irregulares (PRH), y fue financiado por el BID (US\$ 43 millones) y el propio Estado local (casi US\$29 millones). El BID inscribía este aporte en el marco de su estrategia de reducción de la pobreza en el país, que apoyaba "proyectos de mejoramiento de barrios que permiten atender de manera costo-eficiente las necesidades del gran número de personas que viven en condiciones de marginalidad urbana, al tiempo que introduce componentes de reducción de riesgo social y mecanismos de participación comunitaria en el planeamiento, ejecución y consolidación de esas intervenciones” (BID, 2000: 3, negritas del autor). Era explícita la preocupación del organismo por evitar conflictividad social en las villas en años de recesión económica.
13. Instituto del PSP, dedicado a promover la candidatura a intendente de Hermes Binner. 
14. Las acciones del PRH consistieron en apertura de calles, reordenamiento de lotes, entrega de materiales para la construcción de unidades sanitarias en las viviendas de las villas intervenidas, estimulación pedagógica en niños de dos a cinco años, formación en competencias laborales para jóvenes de entre quince y veinticuatro años y apoyo a microempresas.
Las inversiones en infraestructura previstas apuntaban a "incrementar el capital humano y social de estas comunidades, fortaleciendo las redes sociales comunitarias” (BID, 2000: 1), apostando lograr de una vez y para siempre que estos grupos subsistan autónomamente, sin la tutela asistencial del Estado.

En continuidad con el Programa Convivencia, en las representaciones del $P R H$, las villas debían ser encauzadas y volverse barrios formales jerarquizando "los derechos de los habitantes a la inclusión social [radicando] a la gente en el lugar en el que hoy vive” (MR, 2001: 5). Encauzadas no solo "desde la perspectiva del mejoramiento y/o construcción de viviendas e infraestructura, sino incorporando múltiples dimensiones que hacen al desarrollo de las comunidades involucradas” (MR, 2003: 2, negritas del autor).

Si bien para el $P R H$ importaba proveer bienes y servicios tangibles (vivienda en casos de relocalización por apertura de calles, agua corriente, energía, centros de salud), también cobraba relevancia invertir para formar en sujetos, familias y organizaciones barriales, activos, recursos, capacidades que permitiesen "que la comunidad se involucre en la manutención de los servicios brindados, garantizando [...] la sostenibilidad [sic] de las inversiones" (MR, 2002a: 20). La ausencia de cambios a nivel de los sujetos podía mermar la efectividad de las intervenciones proyectadas. De aquí que el $P R H$ se configurase como dispositivo que trascendía lo habitacional ${ }^{14}$ y abordara cuestiones de estimulación psicomotriz, nutrición y entrenamiento laboral enfatizando "las posibilidades de trabajo e ingreso [...] a través de la capacitación emprendedora y empresarial” (MR, 2002b: 5), haciendo del mercado el ámbito desde el cual lograr la integración social (aun en una coyuntura de alto desempleo). El $P R H$ a un mismo tiempo evitaba la dádiva de dar viviendas e inculcaba el sentido del esfuerzo como legitimador del progreso.

Los antecedentes del desarrollo de la comunidad presente en el discurso de las autoridades del DEM se remontan a la década del 60, cuando desde ámbitos estatales y académicos se percibía que las etapas de crecimiento económico (asumidas por la Teoría de la Modernización sobre la base de las teorizaciones de Rоsтоw) que llevarían a los países subdesarrollados de América Latina a equipararse con los del Primer Mundo (vía expansión de la educación y la movilidad social, institucionalización de la democracia representativa, secularización de valores culturales -Nun, 2001-) estaban lejos de sucederse. Consecuentemente, comenzó a pensarse que, al menos en parte, el problema no era estrictamente económico, sino que residía en la 
Las villas de emergencia y sus viviendas en las racionalidades políticas de las autoridades socialistas del Departamento Ejecutivo Municipal de Rosario (1989-2007)

persistencia vernácula de orientaciones valorativas tradicionales. La superación de este panorama pasaba por desarrollar la comunidad para modificar comportamientos individuales, "modificar modos de vida de seres humanos que se resisten al cambio porque están habituados a modalidades antiguas o porque la nueva situación lesiona sus intereses”(ANDER EGG, 1965: 41).

Las autoridades socialistas se hacían así eco de una racionalidad que vinculaba la débil integración de esta población a las pautas culturales hegemónicas con la persistencia de actitudes y conductas que no redundaban en capital humano y social que contribuyese "al fortalecimiento de las diferentes formas de organización de la comunidad” (MR, 1998c: 7). Este concepto de capital humano conecta con las teorizaciones elaboradas por los economistas BECKER, MINCER y Schultz, quienes señalaron los efectos económicos de la educación en tanto inversión cuya rentabilidad futura era pasible de cálculo y que a su vez redundaba en mayores niveles de productividad económica con efectos sobre el desarrollo, el progreso material y la movilidad social intergeneracional. El sujeto era así concebido bajo la conveniencia de incorporar capacidades educativas y laborales con las que mejorar su competitividad en el mercado.

\section{El retorno de la vivienda llave en mano (2002-2007)}

La recuperación económica evidenciada a partir de 2003 y la reducción de los niveles de desempleo y pobreza permitieron a las autoridades del DEM priorizar la atención de otras áreas de gobierno, perdiendo las intervenciones habitacionales la relevancia hasta entonces asignada. El $P R H$ continuó siendo la principal apuesta en materia de vivienda y recuperación barrial, y sumó en 2004 elementos para sostener actividades de agricultura urbana, "herramienta integral [...] para alcanzar los Objetivos del Milenio, como son el mejoramiento de los asentamientos irregulares y el combate del hambre y la pobreza" (MR, 2004b). Las viviendas monoambientales (con baño, cocina y lavadero) construidas por el $P R H$ para relocalizar las familias que abandonaban la villa cubrían $36 \mathrm{~m}^{2}$, y quedaban $66 \mathrm{~m}^{2}$ disponibles en el lote para ampliaciones o el eventual montaje de una huerta con la que contribuir a la propia provisión de alimentos y ocasional generación de ingresos.

En este período, las autoridades del DEM se acogieron a las disposiciones de diferentes programas del Estado nacional vinculados con la construcción de viviendas y al mejoramiento del hábitat, tales como el Programa Federal de Emergencia Habitacional (2003), el Programa 


\section{Martín Carné}

15. Creado por decreto presidencial en 2002, el PJJHD estuvo destinado a jefes/as de hogar (con hijos de hasta dieciocho años o discapacitados de cualquier edad) y con cónyugesconcubinas/os-cohabitantes en estado de gravidez y desempleo; jóvenes desocupados; mayores de sesenta años sin jubilación. Los requisitos para percibir la ayuda económica brindada eran los siguientes: a) certificar escolaridad y salubridad de niños dependientes y beneficiarios; $b$ ) capacitarse para reinsertarse laboralmente; c) participar en proyectos productivos o servicios comunitarios.
Federal de Construcción de Viviendas (2004) y, dentro de este, el Subprograma de Urbanización de Villas y Asentamientos Precarios, iniciado en 2005. El primero fue pensado como una vía con la cual atender rápidamente la doble falta de vivienda y trabajo que afectaba a grandes segmentos poblacionales a lo largo y ancho de todo el país, organizando cooperativas de trabajo tanto con individuos desocupados como con aquellos que recibían transferencias monetarias en el marco del Plan Jefas y Jefes de Hogar Desocupados ( $\mathrm{PJJHD}^{15}$ ), y que debían, paulatinamente, incorporarse al circuito laboral genuino.

$\mathrm{Al}$ darse prioridad como beneficiarios de las viviendas a los cooperativistas jefes de familias numerosas que no tuviesen otras propiedades y percibieran bajos ingresos, las viviendas debían tener una superficie cubierta de $43 \mathrm{~m}^{2}$, con dos dormitorios, baño y cocina, previendo la posibilidad de futuras ampliaciones que ayudasen a evitar riesgos de hacinamiento. Aun cuando la idea de viviendas llave en mano suponía - dada cierta magnitud fija de gasto posible- brindar soluciones habitacionales a un número de individuos menor que si se optase por intervenciones de mejoramiento progresivo, primaba la necesidad de darle una ocupación a la mano de obra todavía no absorbida por el sector privado, estimulando simultáneamente para ella una salida cooperativista.

Las autoridades del DEM buscaron aprovechar estas iniciativas - en particular las de vivienda llave en mano-, pero respetando criterios del $P R H$, abordando el tema de la vivienda "en forma integral, atendiendo cuestiones tales como densidades de población y localización adecuadas, dimensión acotada de los nuevos barrios para generar un entramado social sustentable" (MR, 2004a: 1). Esta posibilidad concreta de ampliar la oferta de viviendas planteaba interrogantes que iban más allá de la urgencia de su construcción, ya que las respuestas que se dieran condicionarían la vida de la ciudad en su conjunto en el mediano y largo plazo. ¿Qué áreas dedicar para ello? ¿Qué escala darles a los futuros barrios para hacerlos sustentables, integrados a la trama urbana preexistente, sin riesgo de constituirse en guetos? La construcción de nuevas viviendas ¿no incrementaría la llegada de migrantes del interior, lo que empeoraría el statu quo? Todos estos interrogantes estaban cruzados además por el imperativo de no derrochar suelo, en tanto bien de creciente escasez y objeto de especulación inmobiliaria.

Sumado al $P R H$ y a las intervenciones impulsadas por el Estado nacional, la construcción de infraestructura, equipamiento y residencias sociales con las que paliar el déficit habitacio- 
Las villas de emergencia y sus viviendas en las racionalidades políticas de las autoridades socialistas del Departamento Ejecutivo Municipal de Rosario (1989-2007)

nal de la población de las villas también se canalizó a través de los denominados Parques Habitacionales Integrados (PHI), ejemplos de Planes Especiales y de Detalle ${ }^{16}$. Contemplados en el Plan Urbano Rosario 2007-2017, los PHI permiten el desarrollo urbanístico a través de inversores privados, quienes asumen los costos de extender a las áreas que reconvertir la infraestructura de comunicaciones (calles internas y accesos), servicios (agua, desagües cloacales y pluviales, gas, electricidad), equipamiento urbano (escuelas, centros de salud, plazas) y cierta cantidad de viviendas sociales a cambio de que el Estado adecúe la normativa que ordena usos del suelo y características de edificación en dichas áreas en función del proyecto inmobiliario presentado. Así, ya no es el desarrollador quien presenta un masterplan para la aprobación del municipio, sino que es este último el que modifica el marco legal para incentivar, inducir y no amenazar la rentabilidad de la iniciativa privada y darle factibilidad a obras edilicias que de otro modo serían antirreglamentarias en el sector de la ciudad que desarrollar o urbanizar. Esta perspectiva se ajustaría a lo que CUENYA señala como el rol de habilitador que ha venido asumiendo el Estado en sus distintos niveles desde fines de los años 90, corriéndose de la producción directa de viviendas para pasar a suministrar "un marco legislativo, institucional y financiero en el cual los emprendimientos del sector privado, de las organizaciones sociales y de los individuos puedan desarrollar efectivamente el sector de la vivienda" (CUENYA, 2005: 3). Los PHI apuntaron a lograr una mayor densidad poblacional en áreas periféricas para hacer un uso más racional del suelo y de los servicios, integrando "en su desarrollo a un sector de heterogénea composición social y profundas carencias” (MR, 2011: 187).

\section{COMENTARIOS FINALES}

El recorrido realizado permite reconocer que las autoridades socialistas del DEM de Rosario, en su reflexión sobre cómo gobernar convenientemente a la población villera de la ciudad desde un plano habitacional, incorporaron - a lo largo del período delimitado- razonamientos y cálculos de tipo neoliberal y workfarista, hecho destacable dada su filiación partidaria.

El pensamiento que en los comienzos de la década del 90 atribuía al Estado nacional la provisión de conjuntos residenciales que aseguren derechos ciudadanos y erradiquen las villas tornó a otro (segunda mitad de dicha década), en el cual la población villera era activa solución de su problema habitacional: respetando su radicación, el DEM abastecería a la villa
16. Los Planes Especiales definen indicadores urbanísticos, superficies $y$ localizaciones destinadas a la construcción de vivienda pública, carácter $y$ tratamiento de espacios públicos, entre otros aspectos. Se utilizan con propósitos tales como reconversión de áreas urbanas desafectadas de su uso original o vacantes, protección del patrimonio urbanístico arquitectónico en áreas de valor singular (MR, 2011). Los Planes de Detalle definen indicadores para una manzana, parcela o áreas de reserva. Ambos son elaborados por el DEM y aprobados por el Concejo Deliberante. 
de materiales e infraestructura de servicios, mientras que los villeros y su comunidad, vía esfuerzo autoconstructivo, mejorarían - lejos de una estrategia de "hábitat digno" (BARRETo, 2010) — sus viviendas según sus gustos y prioridades. Así, el DEM (que buscaba recursos en el Estado nacional y en OIC vía endeudamiento) atendía demandas de una población numéricamente superior a la que se beneficiaría de la más onerosa y lenta construcción de viviendas. En paralelo, para lograr efectos de largo plazo, esta población debía adquirir competencias laborales y hábitos de responsabilidad y emprendedurismo empresarial para abandonar la tutela estatal y subsistir autónomamente vía mercado de trabajo. Por último, en años de recuperación económica posconvertibilidad, las autoridades del DEM idearon herramientas normativas para estimular el lucro de actores privados vinculados con el desarrollo inmobiliario y obtener, como contraparte, infraestructura, equipamiento comunitario y viviendas con que compensar el hábitat villero.

\section{BIBLIOGRAFÍA}

ANDER EGG, Ezequiel (1965) Metodología y práctica del Desarrollo de la Comunidad. Humanitas, Buenos Aires. BALLENT, Anahí (2007). "Políticas de vivienda, arquitectura doméstica y cultura del habitar". En: Población y bienestar en la Argentina del primero al segundo Centenario. Edhasa, Buenos Aires.

BANCO INTERAMERICANO DE DESARROLLO (2000). "Programa Rosario Hábitat - Programa Integral de Recuperación de Asentamientos Irregulares”. BID, Washington.

BARRETO, Miguel Ángel (2010). “El concepto de 'hábitat digno’ como meta de una política integral de áreas urbanas deficitarias críticas, para la integración social desde los derechos humanos”. En: Revista INVI. N. ${ }^{\circ}$ 69. Universidad de Chile, Santiago de Chile.

CASTAGNA, Alicia et ál. (1997). "Incidencia de la pobreza en el Gran Rosario”. Ponencia presentada en la XXXII Reunión Anual de la Asociación Argentina de Economía Política. Organizado por la AAEP y la UNS del 15 al 17 de noviembre de 1997 en la ciudad de Bahía Blanca, Argentina.

CONCEJO MUNICIPAL DE LA CIUDAD DE ROSARIO (1991). "Diario de sesiones". 10 de diciembre. CMCR, Rosario.

CUENYA, Beatriz (2000). "Cambios, logros y conflictos en la política de vivienda en Argentina hacia fines del siglo XX”. En: Boletín Ciudades para un Futuro Más Sostenible, N. ${ }^{\circ}$ 29-30. Universidad Politécnica de Madrid, Madrid.

DEAN, Mitchell (2006) Governmentality. Power and Rule in Modern Society. Sage, Londres.

DE MARINIS, Pablo (1999). "Gobierno, gubernamentalidad, Foucault y los anglofoucaultianos (O: un ensayo sobre la racionalidad política del neoliberalismo)”. En: Globalización, riesgo, reflexividad. Tres temas de la teoría social contemporánea. CIS, Madrid. 
Las villas de emergencia y sus viviendas en las racionalidades políticas de las autoridades socialistas del Departamento Ejecutivo Municipal de Rosario (1989-2007)

DIARIO LA CAPITAL (1990). “Construirán viviendas para la comunidad toba”. 16 de febrero. Rosario. EQUIPO PARA EL ESTUDIO DE LA VIVIENDA (2001) Vivienda financiada por el Estado en Rosario 1989/1999. UNR Editora, Rosario.

FERNÁNDEZ WAGNER, Raúl (2000). “Teorías en hábitat y vivienda”. En: Maestría en Hábitat y Vivienda. FAUyD (UNMdP) y FAPyD (UNR), Rosario.

FOUCAULT, Michel (1991). “Questions on method”. En: The Foucault Effect. Studies in Governmentality. Harvester Wheatsheaf, Londres. (1999). "Polémica, política y problematizaciones”. En: Estética, ética y hermenéutica. Obras esenciales, Volumen III. Paidós, Barcelona. (2001). "El sujeto y el poder”. En: Michel Foucault: más allá del estructuralismo y la hermenéutica. Nueva Visión, Buenos Aires. (2006) Seguridad, territorio, población. Fondo de Cultura Económica, Buenos Aires. (2007) Nacimiento de la Biopolítica. Fondo de Cultura Económica, Buenos Aires. (2009) Vigilar y castigar. Nacimiento de la prisión. Siglo Veintiuno, Buenos Aires.

GAGO, Verónica (2014) La razón neoliberal. Economías barrocas y pragmática popular. Tinta Limón, Buenos Aires.

GARZIA, María et ál. (2004). "Programa Rosario Hábitat: aprendizajes alcanzados”. Ponencia presentada en el II Congreso Nacional de Políticas Sociales. Organizado por la AAPS y la FCPyS de la UNCu del 15 al 17 de septiembre de 2004 en la ciudad de Mendoza, Argentina.

GORDON, Colin (1991). "Governmental rationality: an introduction”. En: The Foucault Effect. Studies in Governmentality. Harvester Wheatsheaf, Londres.

GRASSI, Estela (2003) Políticas y problemas sociales en la sociedad neoliberal. La otra década infame (I). Espacio Editorial, Buenos Aires.

rial, Buenos Aires

(2004) Política y cultura en la sociedad neoliberal. La otra década infame (II). Espacio Edito-

GRONDONA, Ana y HAIDAR, Victoria (2012). "Más allá de la razón liberal: desbordes, heterogeneidad y contradicción. Un estudio crítico de la perspectiva de los governmentality studies”. En: Astrolabio, N. ${ }^{\circ} 8$. CIECS, Córdoba.

GUBER, Rosana (2004). "Identidad social villera”. En: Constructores de Otredad. Una introducción a la Antropología Social y Cultural. Antropofagia, Buenos Aires.

GUBERMAN, Lucio (2004) Victoria, éxito y fracaso. El Partido Socialista Popular en Rosario, 1989-1995. UNR Editora, Rosario.

HARVEY, David (2007) Breve historia del neoliberalismo. Akal, Madrid.

INSTITUTO DE ESTUDIOS MUNICIPALES (1995). "Programa para el Gobierno Municipal del Dr. Hermes Binner. Plan Estratégico General. Principales medidas de gobierno”. IEM, Rosario.

JARAMILLO, Samuel (1990). "El desenvolvimiento de la discusión sobre la urbanización latinoamericana: ¿Hacia un nuevo paradigma de interpretación?”. En: La investigación urbana en América Latina. Caminos recorridos y por recorrer. Viejos y nuevos temas. Ciudad, Quito. 
KYMLICKA, Will y NORMAN, Wayne (1997). "El retorno del ciudadano”. En Ágora, N. ${ }^{\circ}$ 7. Buenos Aires. MUNICIPALIDAD DE ROSARIO (1994). "Programas urbanísticos de interés social”. Municipalidad de Rosario, Rosario.

(1998a). "Programas sociales. La gestión del Estado Municipal en la construcción de una ciudad solidaria”. Municipalidad de Rosario, Rosario. (1998b). "La ciudad de Rosario del Siglo XXI. Programa de recuperación y transformación urbana”. Municipalidad de Rosario, Rosario. (1998c). "Programa Crecer. Guía de trabajo”. Municipalidad de Rosario, Rosario. (2002a). "Programa Rosario Hábitat. Modo de gestión”. Municipalidad de

Rosario, Rosario. (2002b). “Programa Rosario Hábitat”. Municipalidad de Rosario, Rosario. (2003). "Rosario 1995-2003. Ocho años de transformaciones y participación ciudadana”. Municipalidad de Rosario, Rosario. (2004a). "Gacetilla de Prensa. Mes de agosto". Municipalidad de Rosario, Rosario.

(2004b) Decreto N. ${ }^{\circ}$ 2953. Ratificación acuerdo proyecto Construyendo Barrios Productivos: Integrando la Agricultura Urbana en el Diseño y Desarrollo de la Ciudad. Municipalidad de Rosario, Rosario.

(2011) “Plan Urbano Rosario 2007-2017”. Municipalidad de Rosario, Rosario. NUN, José (2001) Marginalidad y exclusión social. Fondo de Cultura Económica, Buenos Aires.

O’MALLEY, Pat (2004). “Riesgo, poder y prevención del delito”. En: Delito y Sociedad, N. ํ 20. UNL, Santa Fe. PAPALINI, Valeria, CóRDOBA, Marcelo y MARENGO, Leonardo (2012). "Estudios de la gubernamentalidad: la subjetividad como categoría política”. En: Astrolabio, N. ${ }^{\circ}$ 8. CIECS, Córdoba.

PECK, Jamie (2002). "Political Economies of Scale: Fast Policy, Interscalar Relations and Neoliberal Workfare”. En: Economic Geography, N. ${ }^{\circ}$ 3. Clark University, Worcester.

PRADILLA, Emilio (1983). "Autoconstrucción, explotación de la fuerza de trabajo y políticas del Estado en América Latina”. En: El problema de la vivienda en América Latina. Ciudad, Quito.

RAGGIO, Liliana (1995). "Un lugar en la ciudad. Alternativas habitacionales en los tiempos de la crisis”. En: Políticas sociales y estrategias habitacionales. Espacio Editorial, Buenos Aires.

RODRÍGUEZ, Carla et ál. (2007) Producción social del hábitat y políticas en el Área Metropolitana de Buenos Aires: historia con desencuentros. Documentos de Trabajo N. ${ }^{\circ} 49$. IIGG/FSOC-UBA, Buenos Aires.

ROSE, Nikolas y MILLER, Peter (1992). "Political Power Beyond the State: Problematics of Government". En: The British Journal of Sociology, $\mathrm{N}^{\circ}$ 2. The London School of Economics and Political Science, Londres. ROSE, Nikolas, O'MALLEY, Pat, VALVERDE, Mariana (2012). "Gubernamentalidad”. En: Astrolabio, N. ${ }^{\circ} 8$. CIECS, Córdoba.

VARELA, Omar y CRAVINO, Cristina (2008). "Mil nombres para mil barrios. Los asentamientos y villas como categorías de análisis y de intervención”. En: Los mil barrios (in)formales: aportes para la construcción de un observatorio del hábitat popular del área metropolitana de Buenos Aires. UNGS, Los Polvorines. 